\title{
Piroxicam and intracavitary platinum-based chemotherapy for the treatment of advanced mesothelioma in pets: preliminary
} observations

\author{
Enrico P Spugnini*1, Stefania Crispi ${ }^{2}$, Alessandra Scarabello ${ }^{3}$, \\ Giovanni Caruso ${ }^{4}$, Gennaro Citro $^{1}$ and Alfonso Baldi ${ }^{4}$
}

\begin{abstract}
Address: ${ }^{1}$ S.A.F.U. Department, Regina Elena Cancer Institute -, Rome -, Italy, ${ }^{2}$ Gene Expression Core, - Human Molecular Genetics Laboratory, Institute of Genetics and Biophisycs, CNR, Naples, Italy, ${ }^{3}$ Istituto Dermatologico San Gallicano, Rome, Italy and ${ }^{4}$ Department of Biochemistry, section of Pathology, Second University of Naples, Italy
\end{abstract}

Email: Enrico P Spugnini* - info@enricospugnini.net; Stefania Crispi - crispi@igb.cnr.it; Alessandra Scarabello - info@enricospugnini.net; Giovanni Caruso - alfonsobaldi@tiscali.it; Gennaro Citro - citro@ifo.it; Alfonso Baldi - alfonsobaldi@tiscali.it

* Corresponding author

\section{Published: 19 May 2008}

Journal of Experimental \& Clinical Cancer Research 2008, 27:6 doi:10.1 186/1756-9966-276

This article is available from: http://www.jeccr.com/content/27///6

(c) 2008 Spugnini et al; licensee BioMed Central Ltd.

This is an Open Access article distributed under the terms of the Creative Commons Attribution License (http://creativecommons.org/licenses/by/2.0), which permits unrestricted use, distribution, and reproduction in any medium, provided the original work is properly cited.
Received: 3 May 2008

Accepted: 19 May 2008

\begin{abstract}
Malignant Mesothelioma is an uncommon and very aggressive tumor that accounts for $1 \%$ of all the deaths secondary to malignancy in humans. Interestingly, this neoplasm has been occasionally described in companion animals as well. Aim of this study was the preclinical evaluation of the combination of piroxicam with platinum-based intracavitary chemotherapy in pets. Three companion animals have been treated in a three years period with this combination. Diagnosis was obtained by ultrasonographic exam of the body cavities that evidenced thickening of the mesothelium. A surgical biopsy further substantiated the diagnosis. After drainage of the malignant effusion from the affected cavity, the patients received four cycles of intracavitary CDDP at the dose of $50 \mathrm{mg} / \mathrm{m}^{2}$ every three weeks if dogs or four cycles of intracavitary carboplatin at the dose of $180 \mathrm{mg} / \mathrm{m}^{2}$ (every 3 weeks) if cats, coupled with daily administration of piroxicam at the dose of $0.3 \mathrm{mg} / \mathrm{kg}$. The therapy was able to arrest the effusion in all patients for variable remission times: one dog is still in remission after 3 years, one dog died of progressive disease after 8 months and one cat died due to progressive neoplastic growth after six months, when the patient developed a mesothelial cuirass. The combination showed remarkable efficacy at controlling the malignant effusion secondary to MM in our patients and warrants further investigations.
\end{abstract}

\section{Introduction}

Malignant mesothelioma (MM) is a rare, highly aggressive tumor, accounting for less than $1 \%$ of all cancer deaths in the world [1]. This neoplasm arises from the surface serosal cells of the pleural (>90\% of cases), peritoneal, and pericardial cavities and from the tunica vaginalis of the testis [2]. Several epidemiological and clinicopathological studies have shown a correlation between exposure to asbestos and development of pleural mesothelioma [3]; nevertheless, the exact mechanism whereby asbestos induces the mesothelioma is still unknown $[4,5]$. Interestingly, recent studies have proposed a role for Simian Virus 40 large $\mathrm{T}$ antigen (SV40-Tag) in the pathogenesis of human mesothelioma, but there are discordant opinions 
in the scientific literature [6-8] Due to the low incidence of the disease, only few randomized studies have been performed [reviewed in [9]]. The prognosis is generally poor with a reported median survival of 4 to 12 months in either untreated or treated (surgery, radiotherapy, or chemotherapy) patients [10]. Moreover, mesothelioma has proven resistant to classical chemotherapeutic and radiation regimes and the natural history has not been influenced by standard therapy [11]. Various drugs have been tested in different combinations so far; among the most commonly employed are doxorubicin, cyclophosphamide, cisplatin (CDDP), carboplatin, gemcitabine, and pemetrexed [11-15]. Of interest, the combination of these drugs, with the exception of pemetrexed, does not appear to provide any clear advantage over mono-therapy [9]. Therefore, there is need of more effective therapies, possibly based on the most recent discoveries on the molecular events involved in mesothelioma pathogenesis and progression. Our research group has recently demonstrated that piroxicam, a commonly used NSAID and COX-inhibitor, has the capability to potentiate the chemotherapic effects of cisplatin on mesothelioma cells, both in vitro and in vivo [16]. This tumor has been infrequently reported in dogs [17] and even more rarely described in cats [18-24]. Moreover, treatment has been limited to palliation with corticosteroids or repeated drainage of malignant effusion, or intracavitary platinum coumpounds $[24,25]$.

A recent study in a mouse model has suggested a potential synergic action between piroxicam and platinum compounds for the treatment of orthotopic mesothelioma xenografts [16].

\section{Materials and methods}

Privately owned companion animals (two dogs and one cat) with MM were enrolled to receive the combination of platinum compounds and piroxicam.

MM was diagnosed by means of ultrasonographic examination confirmed by histopathologically examination of biopsy specimens.

\section{Treatment protocol}

After tumor biopsy or debulking, dogs received daily piroxicam at the dose of $0.3 \mathrm{mg} / \mathrm{kg}$ PO for 4 months and CDDP at the dose of $50 \mathrm{mg} / \mathrm{m}^{2}$ every three weeks intraperitoneally, for a total of four doses. The patients had a complete blood cell count, biochemical profile and urinalysis performed 7 days after each chemotherapy. A ultrasonographic exam was performed on a monthly basis to check for effusion secondary to malignancy.

The cat was treated with injectable piroxicam, (in order to better dose the drug), given at the dose of $0.3 \mathrm{mg} / \mathrm{kg} \mathrm{SC}$ every other day [26] for 4 months and carboplatin at the dose of $180 \mathrm{mg} / \mathrm{m}^{2}$ (every 3 weeks) for a total of four doses. Carboplatin was chosen since systemic administration of CDDP causes fatal pulmonary edema in cats [26]. The patient had a complete blood cell count, biochemical profile and urinalysis performed 7 days after each chemotherapy. A ultrasonographic exam was performed on a monthly basis to check for effusion secondary to malignancy.

\section{Results}

All the enrolled patients well tolerated the treatment protocol without significant side effects that were limited to 1 episode of hematochezia in a dog and in the cat, requiring one week discontinuation of the piroxicam therapy. All the patients had cavitary effusion at the time of presentation: abdominal centesis lead to the removal of $180 \mathrm{ml}$ of fluid as an average. Grossly, the fluid had a yellowish appearance with pink streaks and with occasional filaments of fibrin, microscopically the sample resulted highly cellular showed mesothelial cells isolated or gathered to form clusters, with coarse cromatin, presence of binucleate cells and nuclei of variable size with prominent and large nucleoli (not shown). Abdominal ultrasonography showed thickening of the abdominal serosal surfaces (not shown). Explorative surgery was performed to perform a tumor debulking in a dog and to collect biopsies in the other patients. Histological examination revealed for the two dogs a mixed mesothelioma while the cat had an epithelioid mesothelioma. In figure 1 the histoligical aspect of the epitheliod mesothelioma of the cat is depicted. One of the two dogs is still disease free after debulking and systemic therapy at 2 years, the other dog and the cat had a reduction of the fluid production by $90 \%$ as confirmed by sequential centesis, but developed progressive disease that let to organ strangulation after 8 and 6 months, respectively. Table 1 summarizes the patients' characteristics and follow-up.

\section{Discussion}

As with humans, pets cannot be cured of MM [17]. As with humans with down-staged MM at the time of diagnosis, surgical excision can only be rarely performed in pets [17]. The only exception to this rule may be pericardial MM, where successful palliation can sometimes be achieved by total or partial pericardiectomy, relieving the hemodynamic problems caused by tamponade $[27,28]$. Systemic chemotherapy using mitoxantrone or doxorubicin has been limited to case reports or to small series. Its effectiveness has been limited when used as single modality, while its use as an adjunct to cytoreduction (especially pericardiectomy) has led to reports of prolonged tumour control [29-31]. Probably the best use of chemotherapy for canine mesothelioma is still confined to palliation for advanced disease by means of intracavitary instillation. This 
Table I: Individual data and response to therapy in 3 pets with Malignant Mesothelioma

\begin{tabular}{lllll}
\hline Species & Age & Location & Response & Outcome \\
\hline Syberian husky & 9 & peritoneum & 24 months & NED \\
Mixed Breed & II & peritoneum & 8 months & Dead, PD \\
DSH & 13 & peritoneum & 6 months & Dead, PD \\
\hline
\end{tabular}

$\mathrm{DSH}=$ domestic short hair, NED = no evidence of disease, $\mathrm{PD}=$ progressive disease

approach is well tolerated and is capable of significantly decrease the amount of fluid released by the mesothelioma, furthermore it seems to induce tumor shrinking for a limited amount of time. A review of the literature showed that, in a small cohort of 6 dogs, treatment with intracavitary cisplatin resulted in survival times approaching one year in 5 patients [25]. Unfortunately the low penetration of the drug within the mesothelial layers (2-3 $\mathrm{mm}$ in depth) limits its usefulness in case of bulky disease. The use of other drugs such as tetracycline, talk, or bleomycin (Spugnini EP, personal observation) to induce pleurodesis has been unrewarding [32,33]. Our protocol showed to be highly tolerable by our patients and proved to successfully palliate the malignant effusion secondary to $\mathrm{MM}$ in two pets and was capable to induce a long term control in the third. Interestingly, none of the dogs had haematological or gastrointestinal toxicities, in particular vomiting that is one of the limiting factors to the use of cisplatin in dogs. Also the cat tolerated the therapy without side effects.

In conclusion, considering that there are not established chemotherapy protocols for pets with $\mathrm{MM}$, the combination of intracavitary platinum compounds coupled with piroxicam should be further evaluated, also in view of the many similarities shared by canine and feline $\mathrm{MM}$ with that of humans. In fact, it has been shown in several

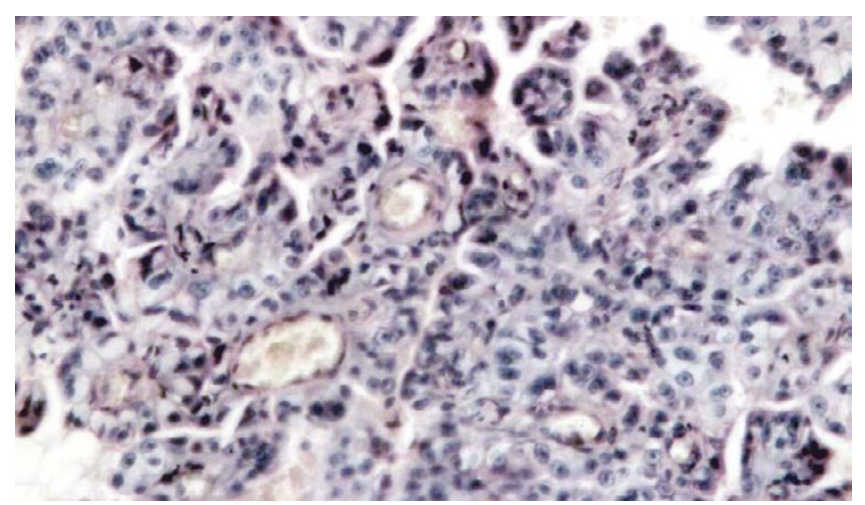

Figure I

Malignant diffuse mesothelioma of epithelial type, forming dense sheets of tumor cells (Hematoxylin/Eosin, Original magnification $10 \times 40)$. research articles that veterinary cancer patients should be considered valuable models for the study of novel approaches such as chemosensitizers, immune modulators, imaging studies and new delivery systems for locoregional therapy [34]. However, results should be evaluated with caution since it's likely that $\mathrm{MM}$ has a more benign biological course in dogs than it does in people and this has to be considered in evaluating uncontrolled case reports of 1 year survival in the dog.

\section{Authors' contributions}

EPS performed the experiments and wrote the paper together with $\mathrm{AB}$. $\mathrm{SC}$, $\mathrm{AS}$ and $\mathrm{GC}$ participated in the design of the study and performed the histological staining. GC conceived of the study, and participated in its design and coordination. All authors read and approved the final manuscript.

\section{Acknowledgements}

This work has been supported by "Grant 2006" and "PROJECT FIRB/MUR (RBIPO6LCA9-009) Grant"of the Italian Ministry of Health to E.P.S and G.C., and by grants from FUTURA-onlus, AIRC, MIUR, Ministry of Health and Second University of Naples to A.B.

\section{References}

I. Robinson BWS, Musk AW, Lake RA: Malignant mesothelioma. The Lancet 2005, 366:397-408.

2. Peto J, Decarli A, La Vecchia C, Levi F, Negri E: The European mesothelioma epidemic. Br J Cancer 1999, 79:666-672.

3. Mossman BT, Chung A: Mechanisms in the pathogenesis of asbestosis and silicosis. Am J Respir Crit Care Med 1998, I 57:| 666-80.

4. Spugnini EP, Bosari S, Citro G, Cognetti F, Baldi A: Human malignant mesothelioma: Molecular mechanisms of pathogenesis and progression. Int J Biochem Cell Biol 2006, 38:2000-2004.

5. Spugnini EP, Campioni M, D'Avino A, Caruso G, Citro G, Baldi A: Cell cycle molecules in mesothelioma: an overview. J Exp Clin Cancer Res 2007, 26:443-449.

6. Carbone M, Rdzanek MA, Rudzinski J], De Marco MA, Bocchetta M, Ramos Nino M, Mossman B, Pass HI: SV40 detection in human tumor specimens. Cancer Res 2005, 65:10120-10121.

7. De Luca A, Baldi A, Esposito V, Howard CM, Bagella L, Rizzo P, Caputi M, Pass HI, Giordano GG, Baldi F, Carbone M, Giordano A: The retinoblastoma gene family $\mathrm{pRb} / \mathrm{p}$ I 05, p I 07, pRb2/p I 30 and simian virus-40 large $T$-antigen in human mesotheliomas. Nat Med 1997, 3:913-916.

8. Manfredi JJ, Dong J, Liu WJ, Resnick-Silverman L, Qiao R, Chahinian P, Saric M, Gibbs AR, Phillips JI, Murray J, Axten CW, Nolan RP, Aaronson SA: Evidence against a role for SV40 in human mesothelioma. Cancer Res 2005, 65:2602-2609.

9. Tomek S, Manegold C: Chemotherapy for malignant pleural mesothelioma. Curr Opin Oncol 2003, I 5: | 48-56.

10. Curran D, Sahmoud T, Therasse P, Van meerbeeck J, Postmus PE, Giaccone G: Prognostic factors in patients with pleural mesothelioma: the European Organization for Research and Treatment of Cancer experience. J Clin Oncol 1998, I 6: |45-52.

II. Chahinian AP, Antman K, Goutsou M, Corson JM, Suzuki Y, Modeas C, Herndon JE 2nd, Aisner J, Ellison RR, Leone L: Randomized phase II trial of CDDP with mitomycin or doxorubicin for malignant mesothelioma by the Cancer and Leukemia Group B. J Clin Oncol I993, I I: I559-65.

12. Samson MK, Wasser LP, Borden EC, Wanebo HJ, Creech RH, Phillips M, Baker LH: Randomized comparison of cyclophosphamide, imidazole carboxamide, and adriamycin versus cyclophosphamide and adriamycin in patients with advanced stage malignant mesothelioma: a Sarcoma Intergroup Study. J Clin Oncol 1987, 5:86-91. 
13. White SC, Anderson H, Jayson GC, Ashcroft L, Ranson M, Thatcher $\mathrm{N}$ : Randomised phase II study of CDDP-etoposide versus infusional carboplatin in advanced non small-cell lung cancer and mesothelioma. Ann Oncol 2000, II:20I-206.

14. Hughes A, Calvert P, Azzabi A, Plummer R, Johnson R, Rusthoven J, Griffin M, Fishwick K, Boddy AV, Verrill M, Calvert H: Phase I clinical and pharmacokinetic study of pemetrexed and carboplatin in patients with malignant pleural mesothelioma. J Clin Oncol 2002, 20:3422-44.

15. Kindler HL, Millard F, Herndon JE 2nd, Vogelzang NJ, Suzuki Y, Green MR: Gemcitabine for malignant mesothelioma: a phase II trial by the Cancer and Leukemia Group B. Lung Cancer 200I, 3I:3II-3I7.

16. Spugnini EP, Cardillo I, Verdina A, Crispi S, Saviozzi S, Calogero R, Nebbioso A, Altucci L, Cortese G, Galati R, Chien J, Shridhar V, Vincenzi B, Citro G, Cognetti F, Sacchi A, Baldi A: Piroxicam and cisplatin in a mouse model of peritoneal mesothelioma. Clin Cancer Res 2006, | 2:6|33-6|43.

17. Head KW, Else RW, Dubielzig RR: Tumours of serosal surfaces. In Tumors of domestic Animals 4th edition. Edited by: Meuten DJ. lowa State Press, Ames; 2002:365-399.

18. Raflo CP, Nuernberger SP: Abdominal mesothelioma in a cat. Vet Pathol 1978, 15:781-783.

19. Akiyama K, Suzuki Y: A case of feline peritoneal mesothelioma with psammoma bodies. Jpn. J Vet Sci 1982, 44:975-979.

20. Bacci B, Morandi F, De Meo M, Marcato PS: Ten cases of feline mesothelioma: an immunohistochemical and ultrastructural study. J Comp Pathol 2006, I34:347-354.

21. Kobayashi Y, Usuda H, Ochiai K, Itakura C: Malignant mesothelioma with metastases and mast cell leukaemia in a cat. J Comp Pathol 1994, I I I:453-458.

22. Rinke M, Rosenbruch M: Pleural mesothelioma in a young cat. Dtsch Tierarztl Wochenschr 2003, I I 0(4): I77- 178.

23. Suzuki $Y$, Sugimura M, Atoji $Y$, Akiyama K: Lymphatic metastasis in a case of feline peritoneal mesothelioma. Jpn J Vet Sci 1985, 47:511-516.

24. Sparkes A, Murphy S, McConnell F, Smith K, Blunden AS, Papasouliotis K, Vanthournout D: Palliative intracavitary carboplatin therapy in a cat with suspected pleural mesothelioma. J Feline Med Surg 2005, 7(5):3।3-316.

25. Moore AS, Kirk C, Cardona A: Intracavitary cisplatin chemotherapy experience with six dogs. J Vet Intern Med 199I, 5:227-3I.

26. Donald Plumb, Ed: Plumb's Veterinary Drug Handbook 5th edition. Ames, Blackwell Publishing; 2005

27. Kerstetter KK, Krahwinkel DJ, Millis DL, Hahn K: Pericardiectomy in dogs: 22 cases (1986-1996). I Am Vet Med Assoc 1997, 2 I I:736-740.

28. Jackson J, Richter K, Launer D: Thoracoscopic partial pericardiectomy in I 3 dogs. J Vet Intern Med 1999, 13:529-533.

29. Ogilvie GK, Obradovich JE, Elmslie RE, Vail DM, Moore AS, Straw RC Dickinson K, Cooper MF, Withrow SJ: Efficacy of mitoxantrone against various neoplasms in dogs. J Am Vet Med Assoc 1991, 198:1618-1621.

30. Ogilvie GK, Reynolds HA, Richardson RC, Withrow SJ, Norris AM, Henderson RA, Klausner JS, Fowler JD, McCaw D: Phase II evaluation of doxorubicin for treatment of various canine neoplasms. J Am Vet Med Assoc 1989, 195: I 580-1583.

3I. Stepien RL, Whitley NW, Dubielzig RR: Idiopathic or mesothelioma-related pericardial effusion: clinical findings and survival in 17 dogs (1 983-1 996). J Small Anim Pract 2000, 41 :342-347.

32. Gallagher LA, Birchard SJ, Weisbrode SE: Effects of tetracycline hydrochloride on pleurae in dogs with induced pleural effusion. Am / Vet Res 1990, 51:1682-1687.

33. Birchard SJ, Gallagher L: Use of pleurodesis in treating selected pleural diseases. Compend Contin Educ Pract Vet 1988, 10:826-832

34. Porrello A, Cardelli P, Spugnini EP: Oncology of companion animals as a model for humans. an overview of tumor histotypes. J Exp Clin Cancer Res 2006, 25:97-105.
Publish with Bio Med Central and every scientist can read your work free of charge

"BioMed Central will be the most significant development for disseminating the results of biomedical research in our lifetime. "

Sir Paul Nurse, Cancer Research UK

Your research papers will be:

- available free of charge to the entire biomedical community

- peer reviewed and published immediately upon acceptance

- cited in PubMed and archived on PubMed Central

- yours - you keep the copyright

Submit your manuscript here:

http://www.biomedcentral.com/info/publishing_adv.asp
BioMedcentral 